This item was submitted to Loughborough's Research Repository by the author.

Items in Figshare are protected by copyright, with all rights reserved, unless otherwise indicated.

\title{
Impact assessment of frequency support by electric vehicles: Great Britain
} scenario 2025

PLEASE CITE THE PUBLISHED VERSION

https://doi.org/10.1109/SIELA.2018.8447085

PUBLISHER

(C) IEEE

VERSION

AM (Accepted Manuscript)

LICENCE

CC BY-NC-ND 4.0

REPOSITORY RECORD

Sanchez, F., Francisco M. Gonzalez-Longatt, and Dimitar Bogdanov. 2019. "Impact Assessment of Frequency Support by Electric Vehicles: Great Britain Scenario 2025”. figshare. https://hdl.handle.net/2134/33489. 


\section{Impact Assessment of Frequency Support by Electric Vehicles: Great Britain Scenario 2025}

\author{
F. Sanchez \\ The Wolfson School: Electronic, \\ Electrical, and Systems Engineering \\ Loughborough University \\ Loughborough, UK \\ F.Sanchez@Lboro.ac.uk
}

\author{
F. Gonzalez-Longatt \\ The Wolfson School: Electronic, \\ Electrical, and Systems Engineering \\ Loughborough University \\ Loughborough, UK \\ fglongatt@fglongatt.org
}

\author{
D. Bogdanov \\ Technical University of Sofia, \\ Faculty of Electrical Engineering, \\ 8, st. Kl. Ohridski Blvd. \\ 1756 Sofia, Bulgaria \\ dbogdanov@tu-sofia.bg
}

\begin{abstract}
A desire to reduce environmental pollution coupled with advances in battery technology are some of the drivers for the massive growth in the use of Electric Vehicles (EVs) worldwide. The objective of this paper is to assess the impact that large groups of EVs, connected to frequency-responsive charging stations, have on the frequency response of the Great Britain (GB) power system during a sudden generation loss event. The assessment considers the minimum expected system's rotational inertia and the predicted EV charging demand in GB for the year 2025. The developed model employs a representative block for the EV clusters which are formed based on the type of frequency support service they can provide. The effects of the expected EV penetration, type of $\mathrm{EV}$ charging, charger delay and sensitivity of the control are evaluated. OPAL-RT has been used to run the simulation and perform the assessment. The simulation results highlighted the positive effects of employing EVs as a distributed energy storage system (DESS) in regards to the system frequency response (SFR).
\end{abstract}

Keywords- Electric vehicles, frequency response, OPAL-RT real-time simulation, vehicle-to-grid.

\section{INTRODUCTION}

The proportion of renewable energy sources (RES) in the modern power system has been widely increasing [1]. This is mainly to reduce the carbon dioxide levels in the atmosphere and to reduce the dependence on fossil fuels. These energy sources, however, present high variability and add another level of unpredictability to the energy balance. Furthermore, RES such as photovoltaic (PV) or wind power, inherently provide no contribution to the system's rotational inertia and therefore have a negative impact in the system's frequency response (SFR) following a system frequency disturbance (SFD). Energy storage systems (ESS) are being employed around the world for the provision of grid support and integration of RES [2],[3]. In parallel with the increase of RES integrated in the grid, since 2010 there has been a significant increase in the number of electric vehicles (EVs) on the road. According to the International Energy Agency (IEA), the global EV stock is over 2 million [4], and in the UK, this figure surpasses 140,000 vehicles [5]. Presently the number of EVs in the UK is not so significant to form noticeable effects in the power system, still, the massive adoption of EVs may have negative consequences if not properly managed. For instance, if the charging of the EV is left unmanaged, by the year 2030, an additional demand of around $8 \mathrm{GW}$ could arise at peak time in Great Britain (GB) power system [6]. On the other hand, the use of EVs as DESS can benefit the operation and improve the stability of the grid by providing services such as frequency regulation and fast active power injection [7]. Being able to provide fast-active power injection to the grid, EVs can assist the system operator and ameliorate the effect that the decline of the system's inertia has on the frequency and on its rate of change (ROCOF) following a disturbance.

This paper assesses the impact that large groups of plug-in EVs have on the frequency response of the power system following a disturbance, considering different types of charging strategies. Specifically, the objective is to determine the impact that different factors, namely: (i) penetration of EVs, (ii) type of charging, (iii) delay induced by the EV supply equipment (EVSE) and (iv) sensitivity of the $P-f$ characteristic have on the SFR. A single area power system model that considers the aggregated response of large clusters of charging EVs has been developed and is presented in Section II. Section III presents three different ways to group the EV clusters depending on the charging location and on the $P-f$ characteristic of the frequency response. The simulations are performed in real-time using OPAL-RT hardware for demonstrative purposes. The conditions and scenarios of the simulation are explained in Section IV, and the results are summarized and discussed in Section V. Finally, Section VI outlines the main findings of the paper.

\section{POWER SYSTEM MODEL FOR FREQUENCY RESPONSE}

The classical model for the study of SFR in an isolated system has been expanded to include the effect of EV clusters providing frequency support and it is shown in Fig. 1. In this model, sudden changes in generation $\left(\Delta P_{G}\right)$ or in demand $\left(\Delta P_{L}\right)$ provoke changes in the system frequency $(\Delta f)$. Net generation deficits $(\Delta P)$ cause the frequency to decrease whereas net surpluses cause the frequency to increase. The normalized kinetic energy stored in the rotating masses of the generating machines, at synchronous speed, is modeled by the rotational inertia parameter $(H)$ and the damping parameter $(D)$, 
represents the variation in demand with respect to the frequency deviation. The generators response to frequency changes is modeled by the speed-droop parameter $(R)$, and the time constants of the speed governor $\left(T_{G}\right)$, and the turbine $\left(T_{T}\right)$. The change in the net injected power by the EVs contributing to frequency support is modeled by $\Delta P_{E V}$. Each EV cluster is formed by two blocks: (i) A $P-f$ control block, which outputs the power reference for the cluster depending on the system's frequency and according to predefined ramps and deadbands. (ii) A charger delay block, which models the delay imposed by the EVSE as a first-order transfer function.

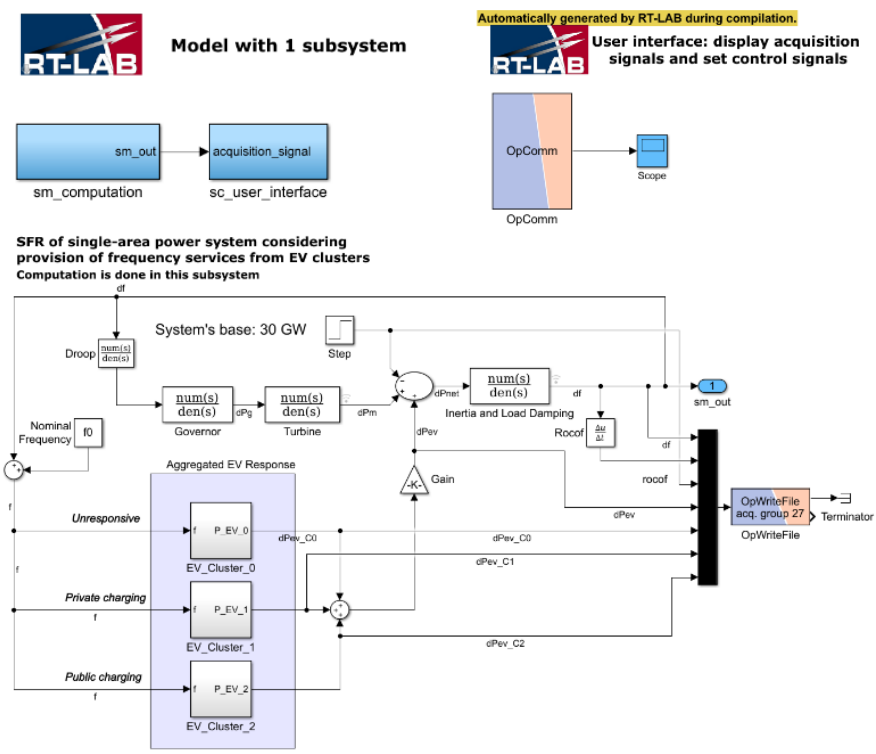

Fig. 1. Overview of the different subsystems of the EV cluster model. RTLAB implementation

\section{FREQUENCY RESPONSE OF EV CLUSTERS}

The frequency response capability of the EV clusters is determined by the EVSE location and by the direction in which energy can flow as presented in Fig. 2. In this figure, $P_{E V}$ represents the injected power from the EV to the grid and $f$ corresponds to the frequency of the power system. EVs or charging stations not providing intentional frequency response are classified as unresponsive. These behave as regular loads which can either be charging or idle, depending on their battery state of charge (SOC), however, the charger will automatically disconnect for frequencies below $47 \mathrm{~Hz}$ or above $52 \mathrm{~Hz}$.

According to the location of the EVSE, charging stations can be broadly classified as private and public facilities [8]. Private facilities are usually located in households, and their charging rate is typically lower than $22 \mathrm{~kW}$, limited by the electrical installation of the premise. Most households in GB are supplied by a single phase, and their main income fuse is sized at between 60 and $80 \mathrm{~A}$ [9]. EVs charging at these facilities are usually connected overnight, and since it takes around $6 \mathrm{~h}$ to charge an average $40 \mathrm{kWh}$ battery with a $7 \mathrm{~kW}$ charger, the vehicle can be charged at a percentage of its rated capacity, thus enabling the provision of frequency response for over frequency events (see Fig. 3).

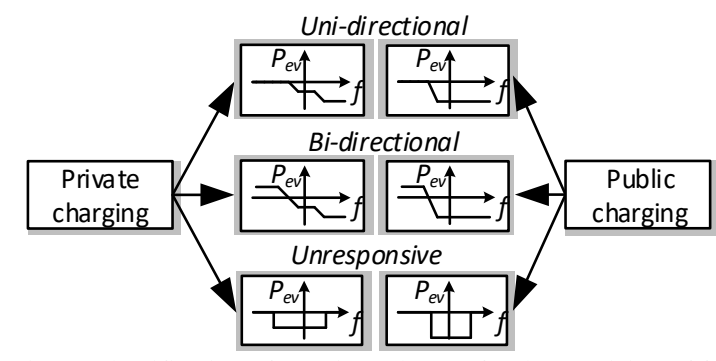

Fig. 2. Classification of EVs into clusters for the provision of frequency response.

On the other hand, public facilities are installed by local authorities on the roads, usually between densely populated areas and in the city centres. The purpose of these stations is to charge in as short time as possible. Therefore the charging rate is typically higher than $22 \mathrm{~kW}$ with upcoming projects reaching charging rates of $150-350 \mathrm{~kW}$ [10], [11]. The EVSE charges the EV battery at the maximum charging rate it is designed to absorb. Hence, frequency containment or regulation is not possible during over-frequency events for EVs charging at these locations.

Depending on the direction of energy flow, the charging stations can be classified as uni or bi-directional. In the first case, power is only allowed to flow from the grid to the EVs for charging, and the only control actions available are to reduce or increase the charging power, depending on the system's frequency. In the second case, in addition to being capable of modifying the charging power, both the EVSE and EV are equipped with the necessary equipment to allow the energy stored in the battery to be discharged to the grid (See Fig. 3).

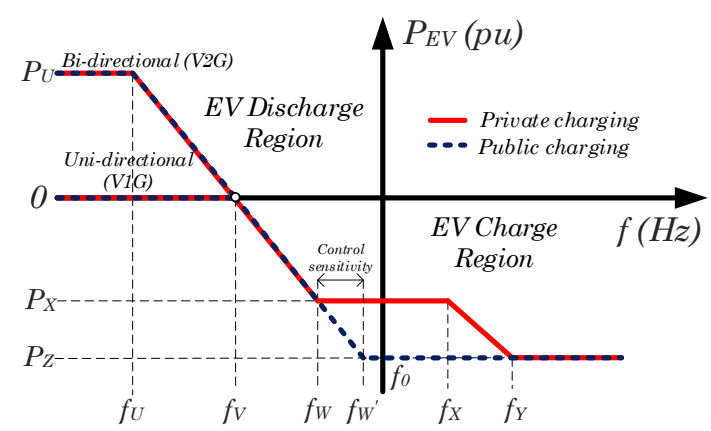

Fig. 3. Charging and discharging profiles of EVs participating in frequency response.

\section{SimUlation SCENARIOS}

Real-time simulations are performed using OPAL-RT hardware for a sudden loss of generation event, which takes place at the time of the lowest rotational inertia in the GB power system. The frequency disturbance is a loss of generation equal to $1,800 \mathrm{MW}$ which corresponds to the infrequent infeed loss risk in the GB system [12]. The equivalent model is divided into two subsystems for real-time simulation as shown in Fig. 1. The model is executed in the software synchronized mode and the fixed time step is equal to $1.0 \mathrm{~ms}$. The lowest estimate for the rotational inertia in the year 2025 is $70 \mathrm{GVA} \cdot \mathrm{s}$ [6]. The speeddroop parameter is equal to $4 \%$ [13], and the load damping 
parameter is equal to $2.5 \%$ [14]. Typical values for the time constants of the speed governor and the turbine are used $\left(T_{T}=\right.$ $300 \mathrm{~ms}$ and $T_{G}=80 \mathrm{~ms}[15]$ ).

In this study, a low EV penetration corresponds to one million vehicles while a high penetration corresponds to eight million [6]. The proportion of EVs connected to public or private charging stations varies throughout the day. According to [16], EVs charging between $22: 00 \mathrm{~h}$ and $07: 00 \mathrm{~h}$ are more likely to be connected to private stations. The base scenario corresponds to the case in which no frequency support is provided by the connected EVs. In scenario A, the effects of the type of charging as well as of EV penetration are explored. In scenario $\mathrm{B}$, the effect of modifying the charger time constant is investigated. Finally, in scenario $\mathrm{C}$, the detection sensitivity of under-frequency events is explored by modifying the deadband of the public charging stations. Table I lists in detail, the different parameters used in the simulation scenarios.

TABLE I. SUMMARY OF THE SIMULATION SCENARIOS.

\begin{tabular}{|c|c|c|c|c|c|}
\hline Scenario & Case & $\begin{array}{c}\text { Type of } \\
\text { charging }\end{array}$ & $\begin{array}{c}\text { EV } \\
\text { Penetration }\end{array}$ & $\begin{array}{c}\text { Charger } \\
\text { time } \\
\text { constant }\end{array}$ & $\begin{array}{c}\text { Response } \\
\text { sensitivity } \\
\boldsymbol{f}_{\boldsymbol{w}}{ }^{\prime}\end{array}$ \\
\hline Base & --- & --- & --- & --- & --- \\
\hline \multirow{2}{*}{ A } & 1.1 & $\begin{array}{c}\text { Uni- } \\
\text { directional }\end{array}$ & Low & $35 \mathrm{~ms}$ & $49.95 \mathrm{~Hz}$ \\
\cline { 2 - 6 } & 1.2 & $\begin{array}{c}\text { Uni- } \\
\text { directional }\end{array}$ & High & $35 \mathrm{~ms}$ & $49.95 \mathrm{~Hz}$ \\
\cline { 2 - 6 } & 2.1 & $\begin{array}{c}\text { Bi- } \\
\text { directional }\end{array}$ & Low & $35 \mathrm{~ms}$ & $49.95 \mathrm{~Hz}$ \\
\cline { 2 - 6 } & 2.2 & $\begin{array}{c}\text { Bi- } \\
\text { directional }\end{array}$ & High & $35 \mathrm{~ms}$ & $49.95 \mathrm{~Hz}$ \\
\hline \multirow{2}{*}{ B } & 1 & $\begin{array}{c}\text { Bi- } \\
\text { directional }\end{array}$ & High & $100 \mathrm{~ms}$ & $49.95 \mathrm{~Hz}$ \\
\hline \multirow{2}{*}{ C } & 1 & $\begin{array}{c}\text { Bi- } \\
\text { directional }\end{array}$ & High & $35 \mathrm{~ms}$ & $49.85 \mathrm{~Hz}$ \\
\cline { 2 - 6 } & 2 & $\begin{array}{c}\text { Bi- } \\
\text { directional }\end{array}$ & High & $35 \mathrm{~ms}$ & $49.985 \mathrm{~Hz}$ \\
\hline
\end{tabular}

\section{Simulations Results AND ANALYSIS}

\section{A. Scenario A: Effect of type of charging and EV penetration}

Fig. 4 (a) shows the frequency response when the disturbance is applied at $t=1.0 \mathrm{~s}$ for the base scenario (without support from EVs) and for the cases with both uni (Case A.1.2) and bi-directional (Case A.2.2) charging. The minimum frequency (frequency nadir) increases from $49.81 \mathrm{~Hz}$ for the base scenario to $49.85 \mathrm{~Hz}$ for the bi-directional case. In general, there is a significant improvement in the frequency response when EVs provide frequency services. Bi-directional charging provides a smaller steady-state frequency deviation and faster stabilization. The maximum ROCOF remains constant because it depends only on the system's normalized inertia constant $(H)$ and on the initial power imbalance $\left(\Delta P_{n e t}\right)$. As it is shown in Fig. 4 (b), the ROCOF has a quick stabilization time in the bidirectional case. The effect of EV penetration on the frequency response is shown in Fig. 5 (a). From this figure, it can be seen that even low EV penetrations result in an improvement of the frequency response.

\section{B. Scenario B: Effect of the EV charger time constant}

The effect of the delay introduced by the EV charger is shown in Fig. 6 (a) and (b). The frequency nadir, as well as the stabilization time, are modified. The steady-state value of the frequency remains unchanged. A bigger charger time constant (Case B.1) results in a slightly lower minimum frequency of $49.845 \mathrm{~Hz}$ which is still a significant improvement over the frequency nadir obtained in the base case of $49.81 \mathrm{~Hz}$.
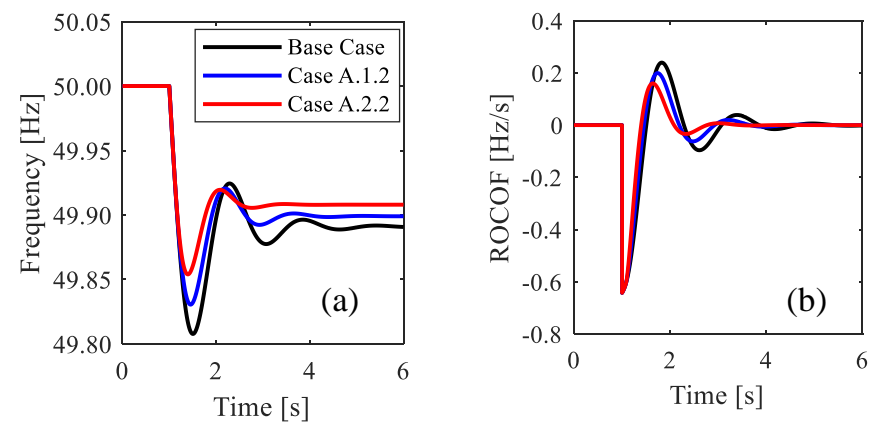

Fig. 4. Effect of the type of charging. (a) Frequency, (b) ROCOF.
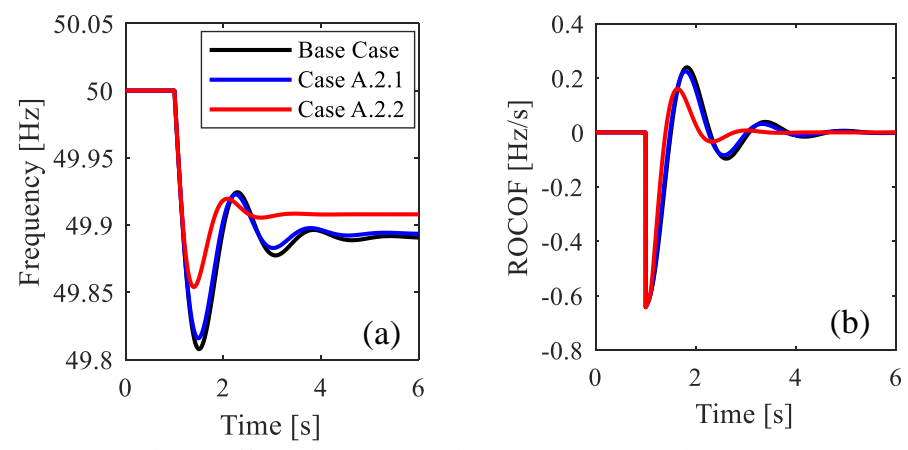

Fig. 5. Effect of EV penetration. (a) Frequency, (b) ROCOF.
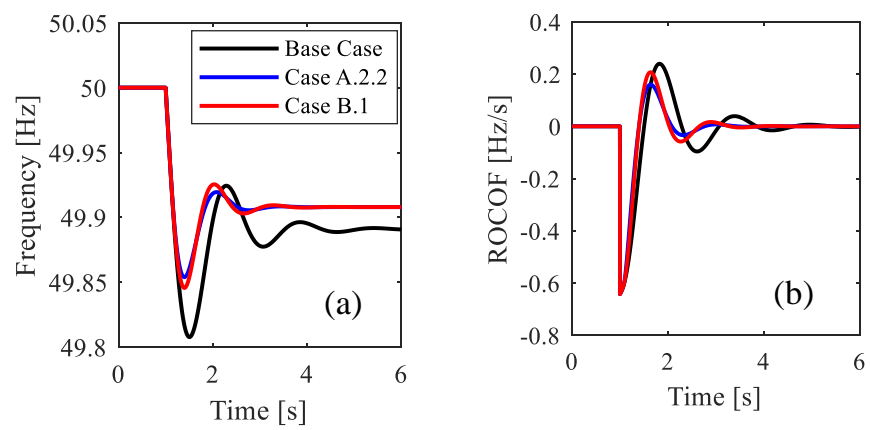

Fig. 6. Effect of EV charger time constant. (a) Frequency, (b) ROCOF.

\section{Scenario $C$ : Effect of the sensitivity of the frequency response}

Fig. 7 (a) gives a comparison of the system's frequency variation for different under-frequency deadbands in the service provision. Case C. 1 represents the less sensitive response $\left(f_{W^{\prime}}\right.$ $=49.85 \mathrm{~Hz}$ ), Case C. 2 represents the more sensitive response $\left(f_{W}{ }^{\prime}=49.985 \mathrm{~Hz}\right)$ and Case A.2.2 represents a middle scenario. For Cases A.2.2 and C.2, the value of the steady-state frequency deviation is improved compared with the base case (without EVs support). The frequency stabilises at $49.917 \mathrm{~Hz}$ and at 49.908 Hz for Cases C.2 and A.2.2 respectively, whereas, for the base case, this figure is $49.891 \mathrm{~Hz}$. The most interesting aspect of this figure is that for Case C.1, even though the 
frequency nadir is improved as compared with the base case, the steady-state value of the frequency is the same as that obtained in the base case. To explain this, it is useful to refer to Fig. 7 (b), which shows the change in the net power injected to the grid by the EV clusters. In the more sensitive Case C.2, the clusters begin to support the system's frequency as soon as it drops to $49.985 \mathrm{~Hz}$ which occurs less than $20 \mathrm{~ms}$ after the loss of generation event. This fast power injection slows down the frequency decrease. Therefore, a higher frequency nadir is obtained. On the other hand, in Case C.2, the clusters begin to support the system's frequency when it drops to $49.85 \mathrm{~Hz}$, which, in this case is after $250 \mathrm{~ms}$, as shown in Fig. 7 (c). For Case C.1, because the frequency stabilises above the service provision threshold, the EVs no longer contribute, and therefore the steady-state response is similar to that observed in the base case.
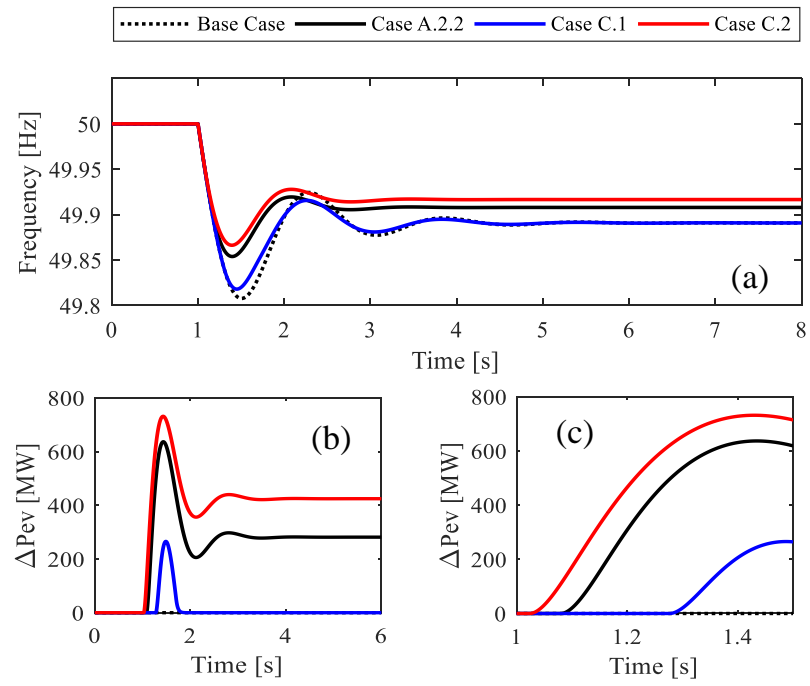

Fig. 7. Effect of the EV response deadband. (a) Frequency, (b) Change in the net injected power by EVs, $\Delta P_{E V}$. (c) Close-up view.

\section{CONCLUSIONS}

This research paper presented an assessment of the potential impact of using EVs to provide frequency support considering the scenario of GB by the year 2025. Simulation results demonstrated that large groups of EVs have the potential to improve the system frequency response following a frequency disturbance. The effects of the EV penetration and the type of charging were considered, and it was found that even at low EVs penetrations, the frequency after a disturbance shows an improvement as compared with the case in which no EVs support is available. In general, the system frequency stabilizes faster and to a value closer to the nominal when bi-directional charging is available. However, the uni-directional charging scheme also leads to an improvement in the SFR because of the load reduction. The delay introduced by the EVSE caused no significant detriment to the SFR in steady-state. Real-time simulations proved to be a valuable tool with which to explore the effects of fast-active power injections into the grid for frequency containment and regulation. A progression of this work is to increase the modelling detail of the EV clusters to be able to devise control schemes that allow them to provide frequency services while managing its SOC and are suitable for real-time simulation.

\section{REFERENCES}

[1] H. Chamorro, F. Gonzalez-Longatt, and V. K. Sood, "Dynamic Measurements of the Wind Power Impact on Power System Inertia and Stability," in International Conference on Innovative Smart Grid Technologies (ISGT Asia 2018), 2018.

[2] "Tesla Prepares 100-MW Battery - Power Engineering." [Online]. Available: http://www.power-eng.com/articles/2017/11/teslaprepares-100-mw-battery.html. [Accessed: 01-Dec-2017].

[3] F. Gonzalez-Longatt, "Effects of Fast Acting Power Controller of BESS in the System Frequency Response of a Multi-Machine System: Probabilistic Approach," in International Conference on Innovative Smart Grid Technologies (ISGT Asia 2018), 2018.

[4] International Energy Agency, "Global EV Outlook 2017," 2017. [Online]. Available: http://www.iea.org/publications/freepublications/publication/globalev-outlook-2017.html. [Accessed: 28-Jul-2017].

[5] Department for Transport, "Vehicle licensing statistics: July to September 2017 - GOV.UK," 2017. [Online]. Available: https://www.gov.uk/government/statistics/vehicle-licensingstatistics-july-to-september-2017. [Accessed: 19-Dec-2017].

[6] National Grid, "Future Energy Scenarios," 2017.Available: http://fes.nationalgrid.com/fes-document/

[7] F. Mwasilu, J. J. Justo, E.-K. Kim, T. D. Do, and J.-W. Jung, "Electric vehicles and smart grid interaction: A review on vehicle to grid and renewable energy sources integration," Renew. Sustain. Energy Rev., vol. 34, pp. 501-516, Jun. 2014.

[8] S. Rajakaruna, F. Shahnia, and A. Ghosh, Plug In Electric Vehicles in Smart Grids Charging Strategies. 2015.

[9] National Grid, "Mass fast charging of electric vehicles," 2017. [Online]. Available: http://fes.nationalgrid.com/media/1281/forecourt-thoughts-v12.pdf. [Accessed: 16-Feb-2018].

[10] "ABB launches what it says is world's fastest EV charger - pv magazine International." [Online]. Available: https://www.pvmagazine.com/2018/04/23/abb-launches-what-it-says-is-worldsfastest-ev-charger/. [Accessed: 30-Apr-2018].

[11] "Enel kicks off the \&quot;E-VIA FLEX-E\&quot; project for the installation of ultra-fast charging stations in Italy, France and Spain enel.com." [Online]. Available: https://www.enel.com/media/press/d/2017/12/e-via-flex-e-eng. [Accessed: 05-Jan-2018].

[12] National Grid, "National Electricity Transmission System Security and Quality of Supply Standard," vol. Ver. 2.3, no. March, p. 59, 2017.

[13] National Grid, E. Transmission, E. Act, G. Britain, and P. Act, "The grid code," no. 5, 2015.

[14] National Grid, "System Operability Framework 2016," 2016.Available:

https://www.nationalgrid.com/uk/publications/system-operabilityframework-sof

[15] Y. Mu, J. Wu, J. Ekanayake, N. Jenkins, and H. Jia, "Primary Frequency Response From Electric Vehicles in the Great Britain Power System," Smart Grid, IEEE Trans., vol. 4, no. 2, pp. 11421150, Jun. 2013.

[16] EA Technology and Manchester University, "An Assesment of how much headroom an Esprit type technology would yield," 2015. 